\title{
Applied Demography in the 21st Century.
}

\author{
Edited by Steve H. Murdock and David Swanson. \\ New York: Springer Science+Business Media B.V. 2008. \\ ISBN: 978-1-4020-8328-0, \$189.00, 374 pages.
}

\author{
Thomas K. Burch \\ Population Research Group \\ University of Victoria \\ tkburch@uvic.ca
}

This volume contains 19 papers on applied demography plus introductory and concluding chapters by the editors. The papers were selected from presentations at the Biennial Conference on Applied Demography, San Antonio, Texas, January 7-9 2007.

The volume's stated aim is to give "an overview of the current range of interests in applied demography," and to illustrate its breadth and depth. As the editors are the first to admit, however, it is not easy to define "applied demography" or to identify its practitioners. Much applied demographic analysis is done by persons with other disciplinary ties - economists, geographers, urban planners, market analysts, etc. And many demographers do some applied work, but do not consider themselves "applied demographers." For the most part, the book represents the discipline as practised and promoted by a sizeable group of demographers associated with the Southern Demographic Association and its well-respected journal Population and Policy Research Review.

In their concluding chapter, the editors describe the field as follows:

... applied demographers are currently characterized by interest in addressing pragmatic questions in specific (generally small) geographic areas for clientele who need to make decisions impacting current or future periods of time. They show particular foci on population estimates and projections and on GIS applications while employing multiple sets of disciplinary knowledge to address such questions. (p. 363)

Elsewhere they note that "estimates and projections are at the core of applied demography" (p. 362). This focus is apparent in the volume; roughly half of the chapters deal with estimates or projections. 
As is usual with books of conference papers, the individual chapters vary greatly in quality, and are only loosely integrated. But taken together they serve the editors' aim of showing the breadth and depth of applied demography as defined above. A cursory reading will give a good idea of what the field is up to these days.

Not all the chapters lend themselves to cursory reading by the uninformed. Chs. 2-5 are detailed discussions of new measurement initiatives at the US Bureau of the Census. Howard Hogan of the Bureau compares (Ch. 2) the new American Community Survey and the older Population Estimates Program with respect to studying population change for small areas (counties, municipalities). "The ACS is designed to provide information about detailed characteristics, specifically the distribution of the population with respect to the many variables formerly measured by the census 'long form'," the form distributed to a sample of all households during the census. The ACS numbers also are based on samples - relatively large at the national and state levels and over several years but not for smaller geographic areas in a given year. Sampling error of estimates can be large. And there are other problems arising from coverage and from a complex statistical process involving many assumptions. In the end, one realizes that the numbers are not data in the sense of direct observation and measurement, but statistically constructed numbers, aka estimates. Hogan is candid on the point: "If users, including government officials and reporters, expect 'census like' accuracy, they will be disappointed." But one wonders how well such numbers will serve multivariate analyses, including GIS studies, or whether they will provide local decision makers with information they don't already know.

An early user of the data, Patricia Becker (Ch. 3), gives a brief but meaty critique of the data "products" from ACS. Her chapter and Hogan's represent a good example of open, constructive dialog about the strengths and weaknesses of official data. In a throwaway line, she makes the sensible suggestion to round percentages provided by ACS to the nearest whole number, thereby avoiding decimals. This is an appropriate treatment of the numbers, although not uniformly used by demographers and other social scientists, who often cling to meaningless decimal digits.

Ch. 4, by statistician Susan Perrone, is a 50 page discussion of efforts to evaluate and to improve the Master Address File, a list of addresses that serves as a basis for both the decennial census and the American Community Survey. Essentially a technical report, it will be of interest mainly to those already deeply involved in address-based analysis.

The remaining chapters cover a wide range of topics: elder abuse; deaths and injuries from fire; demographic influences on church member- 
ship; perception of risk of tuberculosis; disaster demography (e.g., Katrina, 11 September); household consumption and children's time-use in China; employee turnover. Two chapters (19 and 20) discuss the training of applied demographers, one on teaching survey research methods, another on a new Ph.D. program in applied demography at the University of Texas, San Antonio. These chapters help make concrete the editors' and their associates' views of the nature and scope of the field.

Some chapters are more demographic than others. The two chapters on China (Chs. 17 and 18) are sample surveys on consumer expenditures and time use of children respectively, and although interesting, have little content that is distinctively demographic. Similarly, the chapter on fires in Anchorage Alaska (Ch. 12), is demographic only in the sense that census data are used to profile the characteristics of census tracts in which firerelated deaths and injuries are frequent. By the same token, it is the sort of straightforward statistical analysis and interpretation that would be especially useful to local decision makers.

The chapter by Mary Bollinger (Ch. 11) stands out as having some behavioural as opposed to technical-demographic content. Hers is the only chapter with a section subhead containing the word "theory." Bollinger surveys the relevant literature within the framework of a three-stage decision model: first, the perception that one is at risk of tuberculosis; second, the perception that the benefits of appropriate action outweigh the costs; third, that there are no barriers to action. A multivariate analysis of perception of risk of TB and 20 or so co-variates finds all of the model parameters "statistically significant," but explains $14 \%$ of the variance. One wonders if the data were suited to her model.

Several chapters deal with traditional demographic concerns of population projection and estimation, some with a new twist, such as Gregory Stone's detailed account (Ch. 7) of efforts to estimate the population of New Orleans following hurricane Katrina. Nazrul Hoque evaluates population estimates for counties and places in Texas (Ch. 8), comparing 2000 census results to estimates made using three different approaches. The results are sobering, with errors as high as 15 and $20 \%$ for small areas (mostly underestimates) and undercounts of up to 5 and $6 \%$ for larger areas. Hoque suggests averaging estimates made with several different approaches. This idea is based on the questionable assumption that multiple errors necessarily cancel out. Sometimes they do and sometimes they don't. In her analysis they do, at least partially, but one can't count on it in general. In any case, having to make several different estimates using different approaches may not be cost-effective in applied projects, where time and cost considerations tend to be important. 
Beth Jarosz (Ch. 5) and Richard Lycan (Ch. 15) aim to improve estimates by heavier reliance on local tax records. The latter is a refinement of the approach used in studies of medieval populations (precensus), in which historians and archeologists counted "hearths" or houses and then used "multipliers" to estimate population.

Swanson (Ch. 10) suggests an improvement of the standard cohortcomponent method through incorporation of information on census error and providing error bounds on projections that are more nearly objective than those provided by the common high-medium-low projections.

Much of this work on estimates and projections is disturbingly familiar. One gets the impression that most of the innovation in contemporary applied demography involves new topics and new data sources rather than fundamentally new techniques. For example, in much of the estimation and projection work described, internal migration for subnational areas is estimated using the survival ratio method. As old and popular as it is with demographers, this method has a serious inherent weakness: net migration is estimated as a residual (typically small) obtained by differencing two figures for total population - one expected, one actual, but both typically large relative to net migration. Small errors in the population figures can lead to very large errors in estimated net migration, even incorrect signs. It is a reliable method only with near-perfect data.

One of the freshest chapters is by a statistician, Don Warren (Ch. 9), who suggests incorporating projected population into statistical forecasts of nondemographic variables using ARIMA, creating ARIMAX models with one or more demographic co-variates. He identifies what he terms a "oneway disconnect" between statisticians and demographers, and urges statisticians to take population projections more seriously. In his illustration, the model is less apt to "degenerate to a constant," and has smaller error bounds.

I sense a different and perhaps more serious disconnect, between both statisticians and applied demographers on the one hand, and computer modeling on the other. Beth Jarosz (Ch. 5) mentions future plans to develop household population and characteristics estimates for small areas using microsimulation. But no work of that sort appears in this volume. Similarly, Murdock and Swanson (Ch. 21) note that "Users served by applied demographers ... are likely to require more interactive products and more options in the form and types of products" (p. 365). But the estimates and projections featured are of the standard, noninteractive kind.

Applied demography needs to add different kinds of modeling to its repertoire because demographic systems are not self-contained, and because standard projection techniques are, as Keyfitz once put it, "linear and 
open-loop." There are limited feedbacks, even among demographic variables (for example, in cohort-component projections, sex-selective migration has no feedback on age-specific fertility rates). Nondemographic variables typically do not appear in the model. But demographic variables are not exogenous to everything else. Migration, for example, affects but also is affected by housing prices, zoning practices, planning decisions, and the like. The system is more than just a demographic system.

The challenge to 21 st century applied demography, as I see it, is to move away from such heavy reliance on abstract models of self-contained population dynamics and to develop models of populations and communities which are more faithful representations of the concrete systems about which decision makers make decisions. 21 st century demography needs to move beyond 20th century demographic technique. 
